\title{
Clothing Sacred Scriptures
}




\section{Manuscripta Biblica}

Edited by

Martin Wallraff and Patrick Andrist

\section{Volume 2}




\section{Clothing Sacred Scriptures}

Book Art and Book Religion in Christian, Islamic, and Jewish Cultures

Edited by

David Ganz and Barbara Schellewald 
In memoriam Silke Tammen (1964-2018)

ISBN 978-3-11-055767-1

e-ISBN (PDF) 978-3-11-055860-9

\section{Library of Congress Cataloging-in-Publication Data}

Names: Schellewald, Barbara, 1952- editor.

Title: Clothing sacred scriptures : book art and book religion in Christian, Islamic and Jewish cultures / edited by Barbara Schellewald, David Ganz.

Description: 1 [edition]. | Boston : De Gruyter, 2018. | Series: Manuscripta

Biblica ; Volume 2

Identifiers: LCCN 2018018895| ISBN 9783110557671 (print) | ISBN 9783110558609

(e-book (pdf))

Subjects: LCSH: Aesthetics-Religious aspects. | Art and religion. |

Religious literature-History and criticism. | Sacred books-History and criticism.

Classification: LCC BL65.A4 C56 2018 | DDC 203/.7-dc23

LC record available at https://lccn.loc.gov/2018018895

Bibliographic information published by the Deutsche Nationalbibliothek

The Deutsche Nationalbibliothek lists this publication in the Deutsche Nationalbibliografie; detailed bibliographic data are available in the Internet at http://dnb.dnb.de.

(C) 2019 Walter de Gruyter GmbH, Berlin/Boston Typesetting: Integra Software Services Pvt. Ltd. Printing and binding: $\mathrm{CPI}$ books $\mathrm{GmbH}$, Leck

Cover image: Textilseite zum Matthäusevangelium, Codex Aureus von Echternach, um 1040/50. Nürnberg, Germanisches Nationalmuseum, Hs 156142, fol. 17v. @ Germanisches Nationalmuseum Nürnberg

www.degruyter.com 